\title{
Implementation of Wind Mill Monitoring System using IoT and Wi-Fi - Through GSM Protocol
}

\author{
S. P. Vijaya Ragavan, S.Aarthi Suriya, S. Sherine
}

\begin{abstract}
This endeavor presents examinations of using remote sensor frameworks for checking conditions inside wind farms, taking into considerations the specific of such applications. In these circumstances, which are wanted to gain a lot of ground or even work in inconvenient radio conditions with strong diminishing, the fundamental and direct correspondence among source and objective isn't continually possible, due to the partition repression. To beat these facts, we propose a system which continually screens the parameters of the windmill structure and transmits those data's to the cloud using IOT.This system discards the Range force for passing these parameters to the checking structure. [19],[20],[21]
\end{abstract}

Keywords : Wireless sensor networks, attenuation, windmill system, Internet Of Things

\section{INTRODUCTION}

A remote sensor engineer (WSN) is an approach of spatially appropriated self-governing unwired sensors (devices)powered with battery and furnished with merged sensors, information dealing with limits and short-run radio correspondence that ordinarily screen physical or trademark conditions, for example, temperature, sound, weight, improvement, and so on at various site zones. WSNs are regularly utilized for checking and revelation of enormous occasions in various conditions, on liberal zones. Each sensor gathers data from the encompassing condition, performs essential managing and transmits the information to the client utilizing the structure framework. [14],[16], [18]

If there should develop an occasion of wind ranches, WSNs can be utilized both for picking the typical conditions (picking the breeze speed, major for keeping up the turbines in impeccable parameters and explicit a most over the top capacity of the essentialness age), and for checking of a regular working of the breeze turbine so as to maintain a strategic distance from potential harms under serious conditions or their breakdown. The fundamental target for a breeze create creator is to broaden the vitality(energy) obtained inside the purposes of repression puts on it by limitations, for example, trademark, money related and

\footnotetext{
Revised Manuscript Received on August 22, 2019.

Dr.S.P.Vijayaragavan, Department of EEE,Bharath Institute of Higher education and research, Tamilnadu, India. Email: vijayaragavansp@gmail.com

S.Aarthisuriya, Department of EEE,Bharath Institute of Higher education and research, Tamilnadu, India. Email: aarthisuriya2703@gmail.com

Sherine S, Department of EEE,Bharath Institute of Higher education and research, Tamilnadu, India. Email: nssherine@gmail.com
}

focused issues. In the bundling of the structure arrangement of a breeze create, there must be survey specific issues, for example, parts dependability, organize alliance, ground conditions, and so forth which may affect the upgrade and execution of wind ranches.

Wired affiliations have major weights: limit units adaptability, doesn't enable wired gadgets to be shut to the watched miracle, and not in the last thinking about the expansive number of sensors or actuators from a genuine region, the wires incorporate fundamental assistance issues, with surprising expenses.

In the course of action estimation of a breeze Farm, an essential portion is tended to by the general unfaltering quality. The general estimations of the breeze Farm constrain the uses of a grim sensor arrange, dispersed on a wide region, and clearly correspondence utilizing radio and not wires, to keep away from a conceivable underhandedness of the windmill and redesigning the time of achievable power source. [8],[ 10] ,[12]

Sensors are in danger to an expansive grouping of disappointments, from conceivable apparatus or programming breakdowns under common conditions, to those realized by uncommon climate conditions or other unforgiving physical condition in the sensor field.The WSN can in addition miss the mark because of accident, block staying. [13], [15], [17]

\section{SYSTEM DESIGN AND ARCHITECTURE}

In our undertaking we build up a splendid power create by utilizing Wi-Fi and web. The motivation driving structures association is to understand the general power open and absolutely robotized windmill checking. This lessens the establishment and the assistance cost. So far in India the power age and power grid are working freely, at any rate the general power and power stack isn't adjusted. By systems association them we can develops the general ability and request control in addition the assistance. This is finished by IoT. [7], [9] ,[11]

The voltage sensor is used to distinguish the moving toward voltage from the windmill. The structure furthermore recognizes the Oil level present in the system. The banner is given to the controller 
The Oil conditioner sensor is used to screen the condition of the oil. The sensor parameters are given to the microcontroller. The temperature sensor recognizes the temperature of the System.

The Wi-Fi module used here is ESP-8266 module. This is used for giving web source to the microcontroller, as the controller is independent of framework accessibility. The module is used to isolate the sensor's data from the microcontroller.And it moves the data to the server.This proposed system, Parameters like proportion of Power generation,voltage, oil condition and temperature can be watched, controlled and used wherever. This structure effectively reduces the work essential, time and thus the cost. So this could be the charming game plan/thing for the present breeze farms.

\section{BLOCK EXPLANATION}

The sensors joined to the microcontroller, gives the computerized information. The voltage sensor examinations the information acquired and gives it to the microcontroller subsequent to playing out the ADC transformation. The oil sensor examinations the oil nearness in the oil stockpiling tank. The values are given to the microcontroller. In the event that the sensor distinguishes low oil stockpiling, at thapoint an alarm is given to the checking area utilizing Wi-Fi (IOT) module.

The Oil condition sensor is utilized to distinguish the state of the oil. The IOT additionally exchanges the Oil condition to the checking segment. The temperature sensor utilized here is LM35. The sensor distinguishes the temperature of the oil present in the oil stockpiling tank.

\section{COMMUNICATION}

WSNs utilized for recognizing confirmation and seeing of colossal occasions in the breeze homesteads are commonly passed on expansive locale. Thusly, every sensor focus point gets data from the including condition, perform major preparing and transmit the information to client utilizing the structure foundation. A basic approach depends upon sporadically correspondence among sensors and a principal issue (called base station BS) where the purposeful information can be verified and organized. A fundamental damage of this real condition is the over the top proportion of transmitted information, being an interest to improve the exchange off between centrality practical and information precision since a victor among the most persuading parts on the comfort of such structures is the hugeness.

The power supply of all bits is incredibly obliged and it isn't advantageous to supersede regularly the batteries because of the colossal number of the bits in the structure. Considering the way that correspondence centrality utilization is totally higher than the calculation hugeness use, there results the need and the importance of making kept tallies that will require just a constrained extent of correspondence.

Because of the power control of radio correspondence results a restriction on the achievable division between the sender and the gatherer. In like way, the basic and direct correspondence among source and target isn't constantly conceivable, on account of this parcel constrainment, particularly in WSNs utilized for wind create checking, which are needed to increase an enormous measure of ground or even work in problematic radio conditions with solid Weakening. Recollecting the genuine target to comprehend the issue of constrained parcels, a standard strategy framework is the utilization of hand-off stations, where the information packs take multi bounces from the source to the goal. Under such conditions, bundle sending, or controlling, ends up focal. [2 ],[4],[6]

The WSN we used is used for Web Services to drive the sensor data to the server. Also it can gain a power movement from the server page.Based on the banner got, we canperform various exercises. [1], [3],[5]

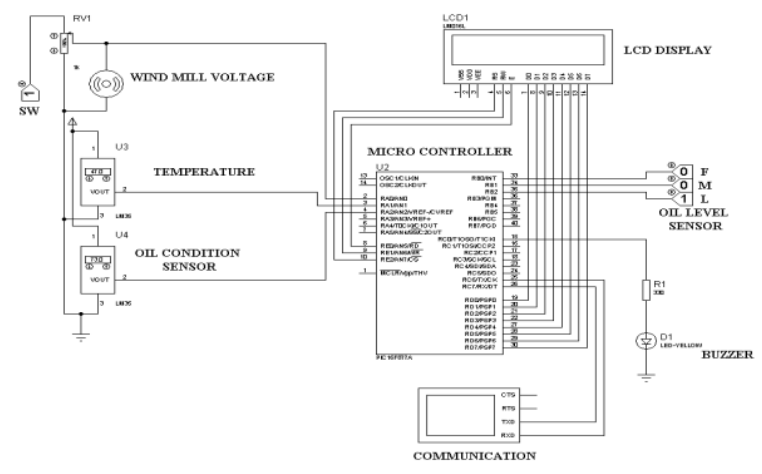

Fig.2.Circuit Diagram of Proposed System

\section{SIMULATION CIRCUIT}

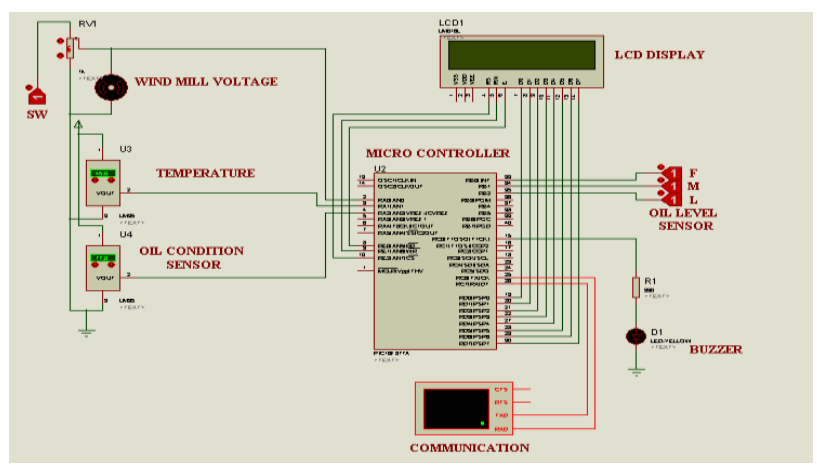

Fig.3.Simulation Circuit of Proposed System 


\section{SIMULATION RESULT}

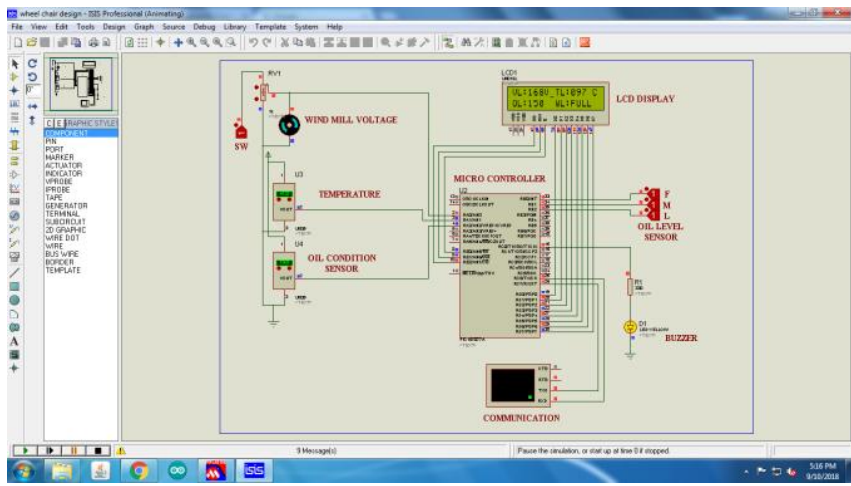

Fig:4 Simulation result of proposed system

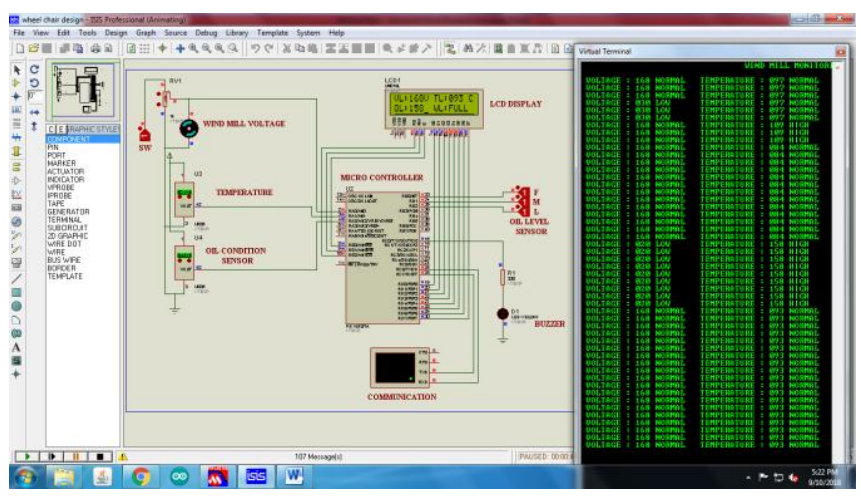

Fig.5.Virtual Terminal Result of Proposed System

\section{SIMULATION EXPLANATION}

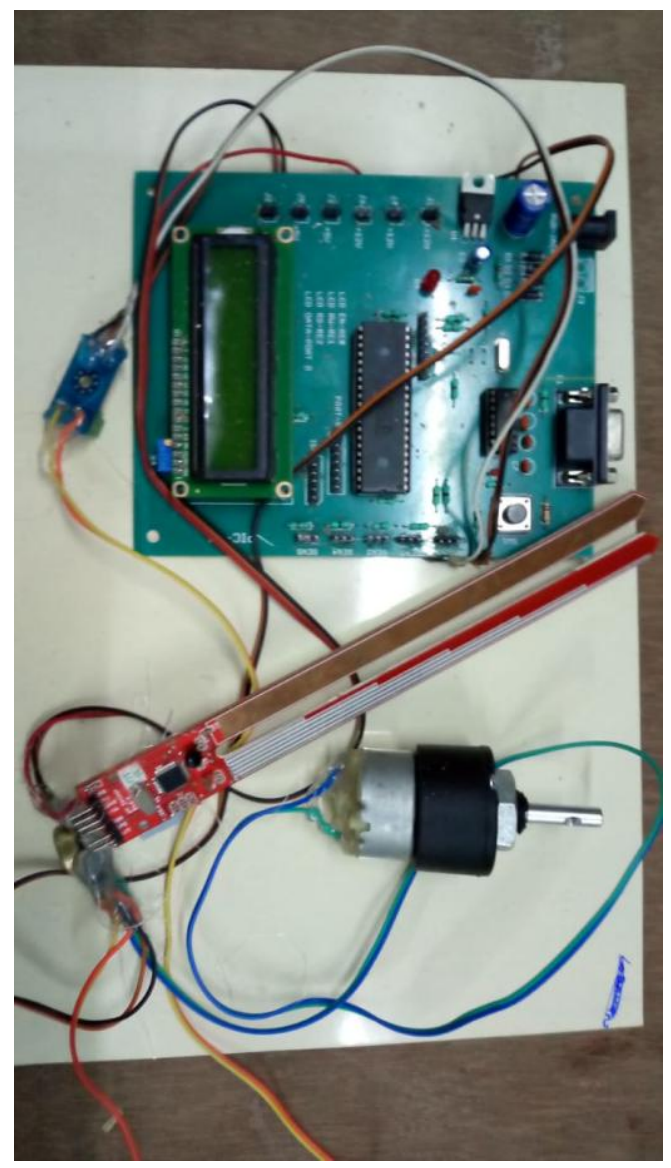

The windmill voltageis persistently checked and its voltage is ceaselessly refreshed to the server. The dimension sensor is a computerized sensor which recognizes the oil level inside the oil stockpiling tank. The Oil condition sensor is a simple sensor which demonstrates the oil condition. The state of the oil is additionally transmitted to the server. The information transmitted are found in the virtual terminal.

\section{CONCLUSION}

Thus the system turns out to be an efficient windmill monitoring system, as it provides an instant data about the parameters of the system using IOT. As the instant data is provided, we can detect any abnormality in the system at the initial stages.

\section{REFERENCES}

[1] Sharma, R.K., Irusapparajan, G. \& Periyaazhagar, D. 2019, "Three-phase symmetric cascading Z-source seven levels multilevel inverter excited by multi carrier sinusoidal pulse width modulation scheme", International Journal of Innovative Technology and Exploring Engineering, vol. 8, no. 10, pp. 4269-4274.

[2] Velavan, R., Bharanidharan, S. \& Sheeba, B. 2019, "EMF pollution Causes, effects and protection", International Journal of Innovative Technology and Exploring Engineering, vol. 8, no. 9 Special Issue 3, pp. 1166-1168.

[3] Saravana, S., Balaji, S., Arulselvi, S. \& John Paul Praveen, A. 2019, "Reliable power quality monitoring and protection system", International Journal of Innovative Technology and Exploring Engineering, vol. 8, no. 9 Special Issue 3, pp. 644-645.

[4] Tamil Selvan, S. \& Sundararajan, M. 2019, "Performance Parameters of 3 Value $8 \mathrm{t}$ Cntfet Based Sram Cell Design Using H-Spice", Internationa Journal of Recent Technology and Engineering, vol. 8, no. 2 Special issue 5, pp. 22-27.

[5] Jac Fredo, A.R., Abilash, R.S., Femi, R., Mythili, A. \& Kumar, C.S 2019, "Classification of damages in composite images using Zernike moments and support vector machines", Composites Part B Engineering, vol. 168, pp. 77-86.

[6] Kathiravan, P. \& Govindaraju, C. 2019, "Design and evaluation of ultra gain isolated DC-DC converter for photovoltaic system", International Journal of Engineering and Advanced Technology, vol. 8, no. 5, pp. 2646-2651.

[7] Kripa, N., Vasuki, R. \& Kishore Kanna, R. 2019, "Realtime neural interface controlled au-pair BIMA bot", International Journal of Recent Technology and Engineering, vol. 8, no. 1, pp. 992-994.

[8] Mohanraj, Meenaa Kumari, M., Philomina, S. \& Jasmin, M. 2019, "In-situ humidity measurement of hydrogen fuel cell car using MEMS sensor", International Journal of Recent Technology and Engineering, vol. 8 , no. 1, pp. 41-43.

[9] Velmurugan, T. \& Prakash, S. 2019, "Artificial intelligent based distribution automation of swift fault detection isolation and power restoration for HT network", International Journal of Innovative Technology and Exploring Engineering, vol. 8, no. 6, pp. 1-6.

[10] Dwarakesh, K. \& Prem Kumar, G. 2019, "Five-level inverter based sequential boost system using fuzzy logic controller", International Journal of Innovative Technology and Exploring Engineering, vol. 8, no. 6, pp. 12-19.

[11] Anne Gifta, A. \& Hemavathi, G. 2019, "Analysis of grid tied solar PV system using ANFIS Algorithm", International Journal of Innovative Technology and Exploring Engineering, vol. 8, no. 6, pp. 312-316.

[12] Jayavel, R., Rangaswamy, T.R. \& Prakash, S. 2019, "Efficient grid management system with renewable and conventional power sources", International Journal of Innovative Technology and Exploring Engineering, vol. 8, no. 6, pp. 287-289.

[13] Hemavathi, G. \& Maheshwaran, S. 2019, "Proportional resonant controlled high gain step-up converter system with improved response", International Journal of Innovative Technology and Exploring Engineering, vol. 8, no. 6, pp. 317-323. 
[14] Periyaazhagar, D. \& Irusapparajan, G. 2019, "Design and completion of asymmetric single phase 27 level cascaded mli for various pwm scheme", International Journal of Innovative Technology and Exploring Engineering, vol. 8, no. 6, pp. 792-797.

[15] Mahalakshmi, V. \& Vijayaragavan, S.P. 2019, "PV based power electronic converters for high voltage DC applications", International Journal of Recent Technology and Engineering, vol. 7, no. 6, pp. 670-674.

[16] Irusapparajan, G., Periyaazhagar, D., Prabaharan, N. \& Rini Ann Jerin, A. 2019, "Experimental verification of trinary DC source cascaded h-bridge multilevel inverter using unipolar pulse width modulation", Automatika, vol. 60, no. 1, pp. 19-27.

[17] Sangeetha, G., Sherine, S., Arputharaju, K. \& Prakash, S. 2019, "On Line Monitoring of Higher Rated Alternator using Automated Generator Capability Curve Administer", Proceedings of the IEEE International Conference on \&amp;quot;Recent Trends in Electrical, Control and Communication\&amp;quot;, RTECC 2018, pp. 176.

[18] Bycil, V.J. \& Wiselin, M.C.J. 2019, "Modeling and analysis of vibration energy harvesting system using piezo stack", International Journal of Mechanical and Production Engineering Research and Development, vol. 9, no. Special Issue 1, pp. 523-533.

[19] Sripada, A., Warrier, A., Kapoor, A., Gaur, H. \& Hemalatha, B. 2018, "Dynamic lateral balance of humanoid robots on unstable surfaces", International Conference on Electrical, Electronics, Communication Computer Technologies and Optimization Techniques, ICEECCOT 2017, pp. 539.

[20] Srinivasan, S., Thirumalaivasan, K. \& Sivakumaran, T.S. 2018, "Performance evaluation of double-output luo converters", Journal of Advanced Research in Dynamical and Control Systems, vol. 10, no. 10 Special Issue, pp. 870-878.

[21] Karthikayen, A. \& Selvakumar Raja, S. 2018, "A skellam distribution inspired trust factor-based selfish node detection technique in MANETs", Journal of Advanced Research in Dynamical and Control Systems, vol. 10, no. 13, pp. 940-949.

\section{AUTHORS PROFILE}

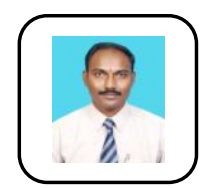

Dr.S.P.Vijayaragavan,Associate Professor,Department of EEE,Bharath Institute of Higher education and Research, Tamilnadu, India

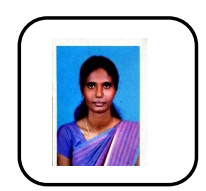

S.Aarthi Suriya,Assistant Professor, Department of EEE, Bharath Institute of Higher education and Research, Tamilnadu, India

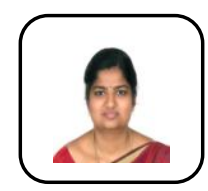

Sherine S, Assistant Professor,Department of EEE, Bharath Institute of Higher education and Research, Tamilnadu, India. 